\title{
Variation in VIP latrine sludge contents
}

\author{
BF Bakare*, KM Foxon, CJ Brouckaert and CA Buckley
}

Pollution Research Group, School of Chemical Engineering, University of KwaZulu-Natal, Durban 4041, South Africa

\begin{abstract}
This study investigated variations in the characteristics of the sludge content from different ventilated improved pit (VIP) latrines and variation in these characteristics at specific depths within each pit. Faecal sludge from 16 VIP latrines within the eThekwini Municipality was collected and laboratory characterisation including moisture content, total and volatile solids, chemical oxygen demand, and aerobic biodegradability was performed. Sludge samples were collected from 4 specific depths within each pit investigated. The laboratory characterisation performed showed that none of the VIP latrines investigated had the same sludge characteristics, and that within a pit sludge characteristics varied with increasing depth in the pit. This supports the motivating hypothesis that, depending on household habits and local environmental conditions, there should be considerable variation in the organic contents, moisture content, non-biodegradable content and microbial population between different pits. This variation with increasing depth within a pit is expected, since fresh material is constantly being added to the pit overlaying older material which might have undergone a certain degree of stabilisation.
\end{abstract}

Keywords: stabilisation, household habits, aerobic biodegradability, sustainable

\section{Introduction}

In South African at present, a considerable number of ventilated improved pit (VIP) latrines and conventional pit latrines in rural and peri-urban settlements around the country and, in particular, within the eThekwini Municipality, are full and require immediate emptying. The challenge is finding an appropriate and sustainable disposal route for sludge evacuated from these full pits. Thus, it is important to determine the characteristics of the sludge present in the pits.

VIPs are used as an anaerobic accumulation system for stabilising faecal matter, urine and other added materials, depending on household habits (Chaggu, 2004), and function as containment for digestion of fresh faeces, and storage of the digested faeces, and are designed primarily for the storage of the digested solids (Mara, 1996). The content of any particular VIP latrine consists of a wide range of materials. It is impossible to predict the composition of the material present in any particular pit without physically observing the contents of the pit or digging it out, since many households make use of the pit either for their basic sanitation needs or for both sanitation needs and dumping of household solid refuse. In addition to faecal matter a large variety of other material such as newspaper, magazines, broken glass, bottles, rags, plastic bags and other household waste materials could be found in a pit (Fig. 1).

The objective of this study was to investigate the variation in the characteristics of VIP latrine sludge content and the degree of stabilisation of sludge content with increasing depth as one excavates the pit. The laboratory results of samples collected from 16 VIP latrines at 4 specific depths within each pit latrine are described in this paper.

\footnotetext{
* To whom all correspondence should be addressed.

푤 +27 31 9077359; fax: +27 31 9077307; e-mail: bbf2ng@yahoo.com
}

Received 18 July 2011; accepted in revised form 27 June 2012.

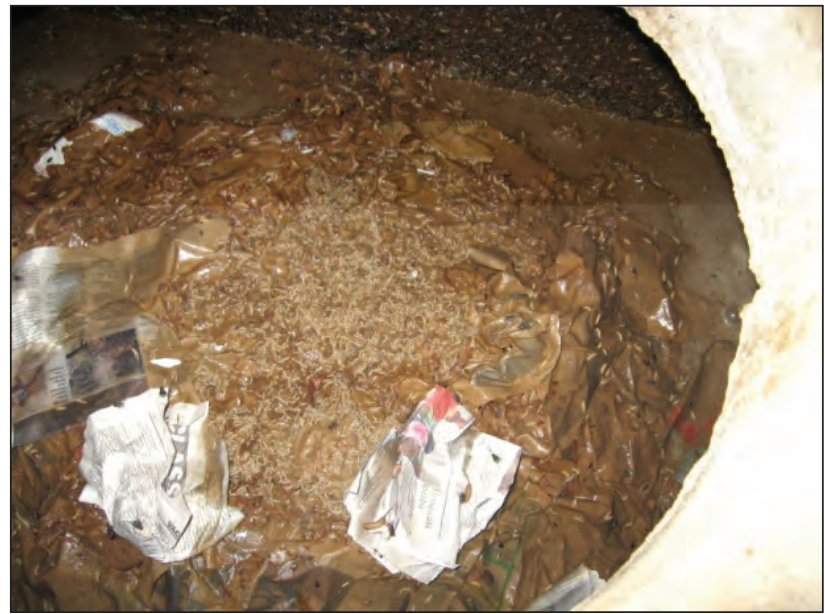

(a) $Q$ section Umlazi

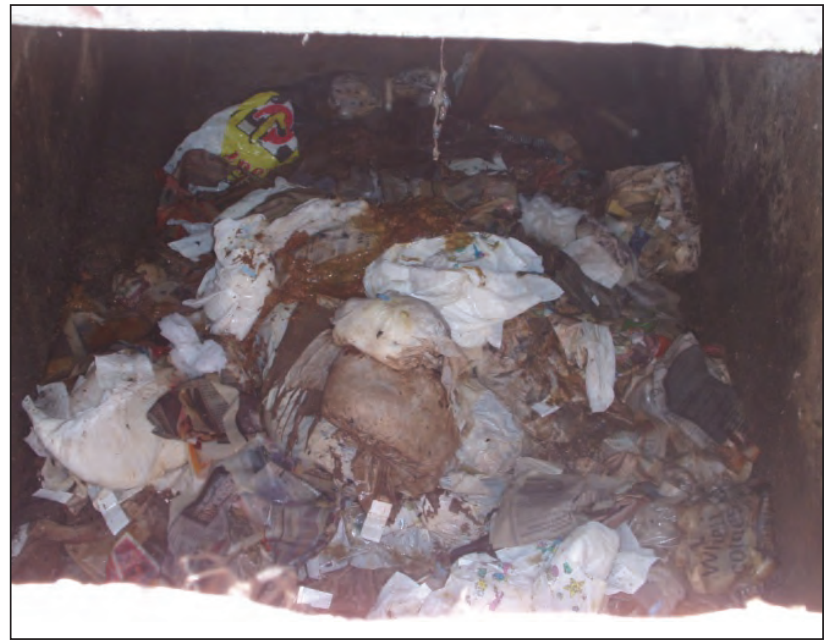

(b) Mariannhill

\section{Figure 1}

Typical content of a pit latrine from 2 pits located in different communities within eThekwini Municipality 


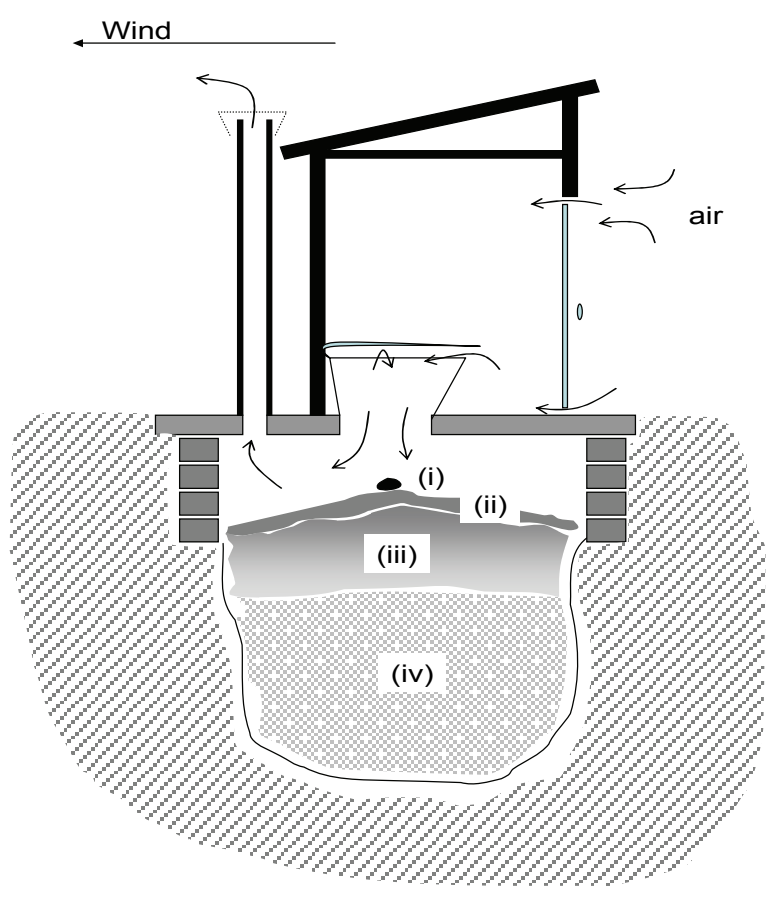

Figure 2

Diagram showing the different theoretical layers within a pit

\section{Materials and methods}

\section{Sampling techniques}

Buckley et al. (2008) proposed that the faecal sludge portion within any pit latrine comprises of 4 theoretical categories as shown in Fig. 2:

- The first category (i) contains sludge in which readily biodegradable components are still present and in which rapid aerobic degradation is taking place

- The second category (ii) is the layer in which aerobic degradation of hydrolysable organic material takes place at a rate limited by aerobic hydrolysis of complex organic molecules to simpler compounds

- The third category (iii) is suggested to be an anaerobic layer due to the occlusion of oxygen by covering material; anaerobic degradation in this layer is controlled by the rate of anaerobic hydrolysis of complex organic molecules to simpler molecules

- The fourth category (iv) which is the lowest and bottom layer of the pit; the sludge component in this layer has attained a significant degree of stabilisation and no further stabilisation of organic material occurs within the remaining life span of the pit

This hypothesis applies when there is relatively little movement of material in the pit after original addition, such that the age of the material in the pit (amount of time since it was deposited) increases with increasing depth, and is therefore probably limited to relatively dry pits (no free liquid surface). In this case, the amount of biodegradable solids as a fraction of total solids should decrease with increasing depth for samples collected from the surface layer, Layer (i) through to Layer (iii) and should remain constant in Layer (iv). This would be observed as decreases in chemical oxygen demand
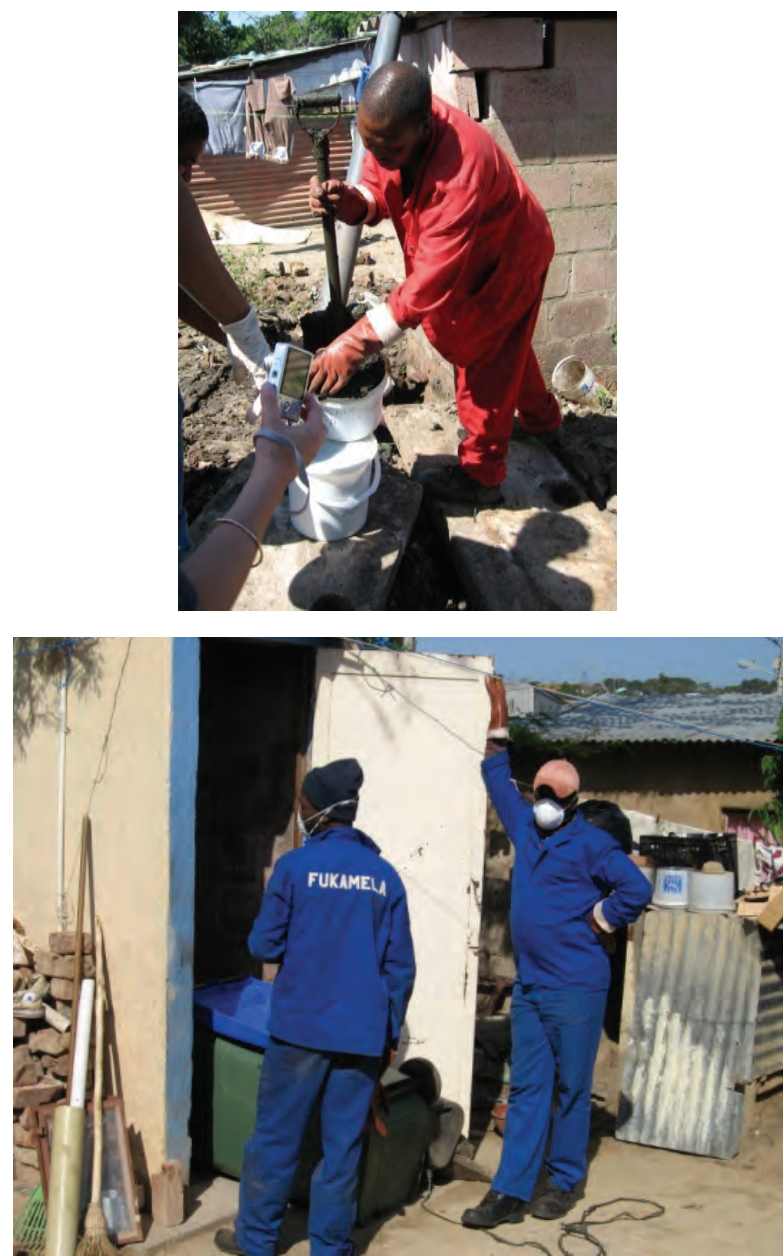

Figure 3

Pit emptying and sampling techniques

(COD), volatile solids (VS) and biodegradability of pit latrine sludge content as a function of total solids as one digs from the surface layer down to the bottom layer of the pit. It should also be noted that depending on the household habits and local environmental conditions, and the history of these factors, there will be considerable temporal variations in the moisture content, organic content, non-biodegradable content and microbial population of new material as it is added to the pit, and therefore variations will occur within the pit, and similarly large variations will occur between different pit latrines.

Based on this proposition and in order to achieve the study objective, samples were collected from 4 different depths within each pit:

- Top level (surface material)

- After 0.5 m emptying depth

- After 1.0 m emptying depth

- Bottom level

Each pit was emptied manually using a shovel, bucket and waste skips. The emptying process was done by Fukamela contractors and general assistance was given by the eThekwini Water and Sanitation unit. Samples were collected at each location within the pit as the digging process was carried out. Each sample was collected in a plastic bag and placed in the collection bucket. Plastic bags were used so as to limit the amount of air the sample came in contact with, after which the samples were taken to the laboratory and stored in the 
cool room at $4{ }^{\circ} \mathrm{C}$ before testing. Figure 3 shows how samples were collected.

\section{Laboratory characterisation of samples}

Laboratory characterisation included: moisture contents, solids (total and volatile solids), chemical oxygen demand (COD), and aerobic biodegradability. The moisture content, solids, and COD analysis were performed using standard methods (APHA, 1998). The aerobic biodegradability tests involved suspending $50 \mathrm{~g}$ of well-mixed sample in $1 \ell$ of tap water in a large Erlenmeyer flask; the mass of the suspension was recorded. The suspension was then analysed for total COD and aerated with saturated air for 5 days. The mass of the suspension was recorded, after which samples were taken and analysed for total COD. The biodegradable COD content of the sample was calculated as the ratio of the amount of COD reduced by the aeration process to the original COD content of the suspension, and corrections were made for moisture loss through evaporation. The principle of the method used was that vigorous aeration of sludge samples suspended in water for an extended period will result in biological oxidation of all the organic material in the sludge sample that is inherently biologically oxidisable. Thus the difference in COD content before and after aeration is the biodegradable COD of the sample (g biodegradable COD/gCOD).

Each analysis was carried out in triplicate on each of the samples collected and the average of each analysis was computed for the final results. Accuracy checks conducted on each analysis carried out on the samples confirmed that the overall coefficient of variance was less than $10 \%$.

\section{Results}

The moisture content results are shown in Fig. 4.

The moisture content of the pit materials can influence the microbial activity. As shown in Fig. 4a, within each pit there was considerable variation $(p<0.05)$ in the moisture content at different layers of the pit. The moisture content showed a general decrease with increasing depth. This suggests that most of the pit latrines investigated were located in areas where most of the pit volume was above the level where free groundwater can be found, at the time that the pit was sampled. This implies that there was a net movement of water out of the pit. As shown in Fig. 4c, the average total moisture content within each pit analysed was about $60 \%$; this falls within the range reported in the literature (50 to $60 \%$ of the total weight) to be adequate for microbial activity (Peavy et al., 1985; EPA, 1995). Hence, biological activity in most of the pits would not have ceased due to low moisture content.

The general trend in the moisture content results for all pits was a decrease from the surface to $1 \mathrm{~m}$ depth and little to no change from $1 \mathrm{~m}$ to $1.5 \mathrm{~m}$. An atypical result was observed for Pit 16, where there was a gradual increase in the moisture content of the material in the pit from the surface of the pit to the bottom of the pit. This suggests that there might be water ingress from somewhere else, which may be from groundwater or a leaking tap nearby. On average the mean moisture content of the surface layer of the pit was found to be $77 \%$ and of the bottom layer was found to be $67 \%$, as shown in Fig. $4 \mathrm{~b}$. In eight of the pit latrines investigated, the moisture content at the bottom was substantially higher than the moisture content of the $1 \mathrm{~m}$ depth sludge samples. These pit latrines may have been located such that the water table was higher than the

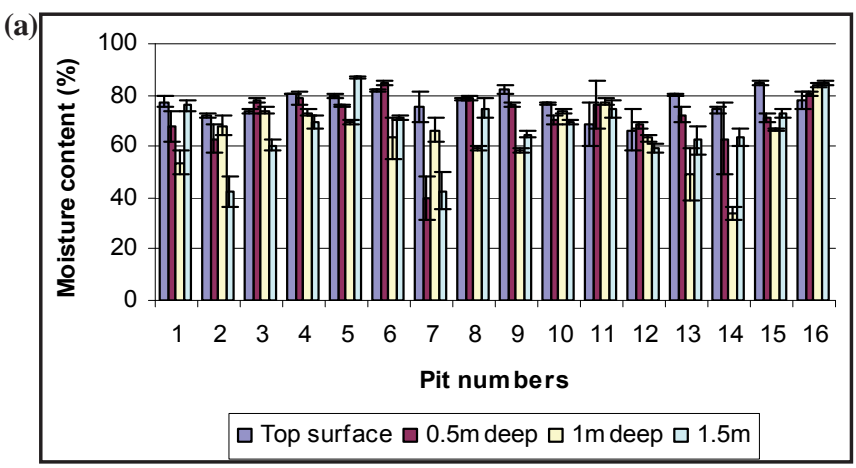

(b)
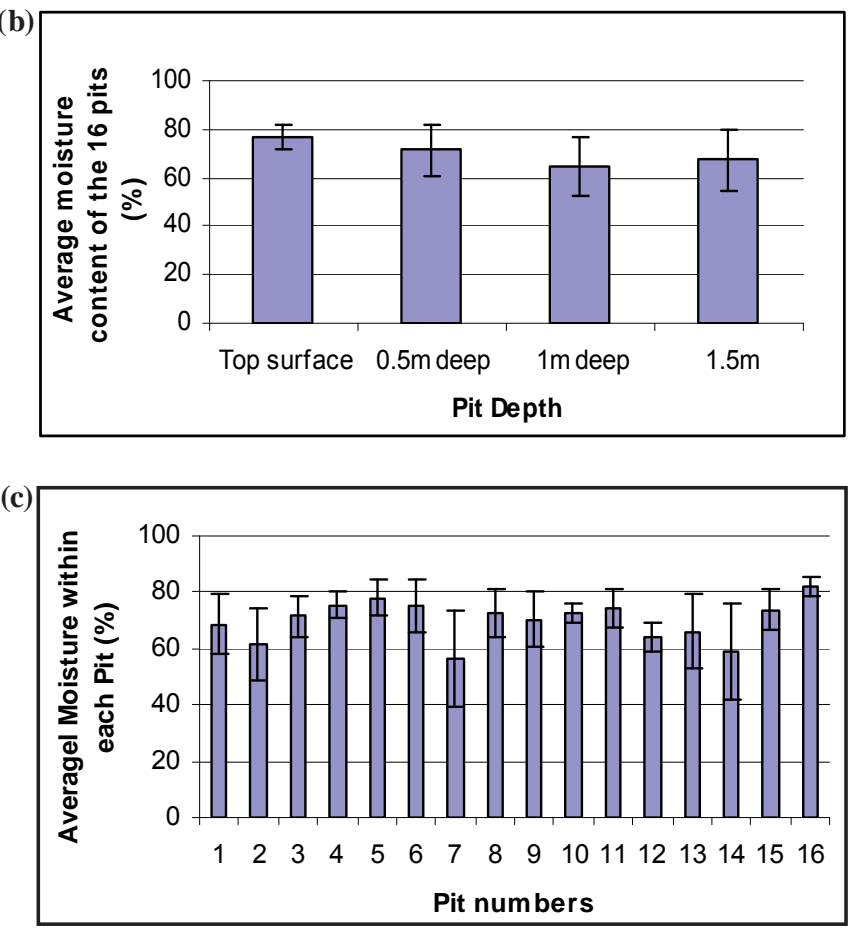

Figure 4

Moisture content characterisation results (a) for each of the 16 pits from different layers within each pit (b) average moisture content at each layer for the 16 pits (c) average moisture content within each of the 16 pits. Error bars represent standard deviation.

bottom of the pit. The average moisture content for all of the 16 pits analysed decreased down the pit, with an increase at the bottom layer as shown in Fig. 4b. Regression/correlation analysis was performed using SPSS15 and Curve Expert 1.3 and showed that there was not a significant linear relationship between the average moisture content and depth within the pit. This supports the earlier statement that most of the pit latrines investigated were located in areas where most of the pit volume was above the level where free groundwater can be found at the time that the pit was sampled, and as such there might be a net movement of water out of the pit. Univariate analysis of variance was carried out using SPSS15 with a post-hoc Scheffe test to compare mean values of moisture of the different samples collected at different depths. It was found that only moisture contents from the top surface and bottom layer of the pit were significantly different from each other.

The volatile solid characterisation result is presented in Fig. 5. 


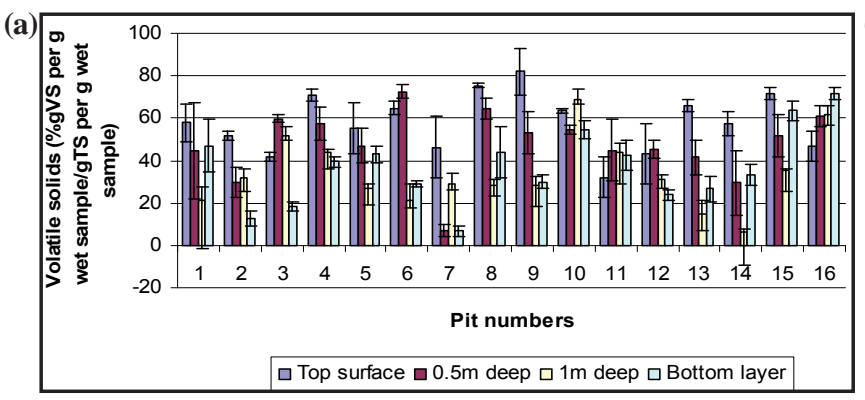

(b)
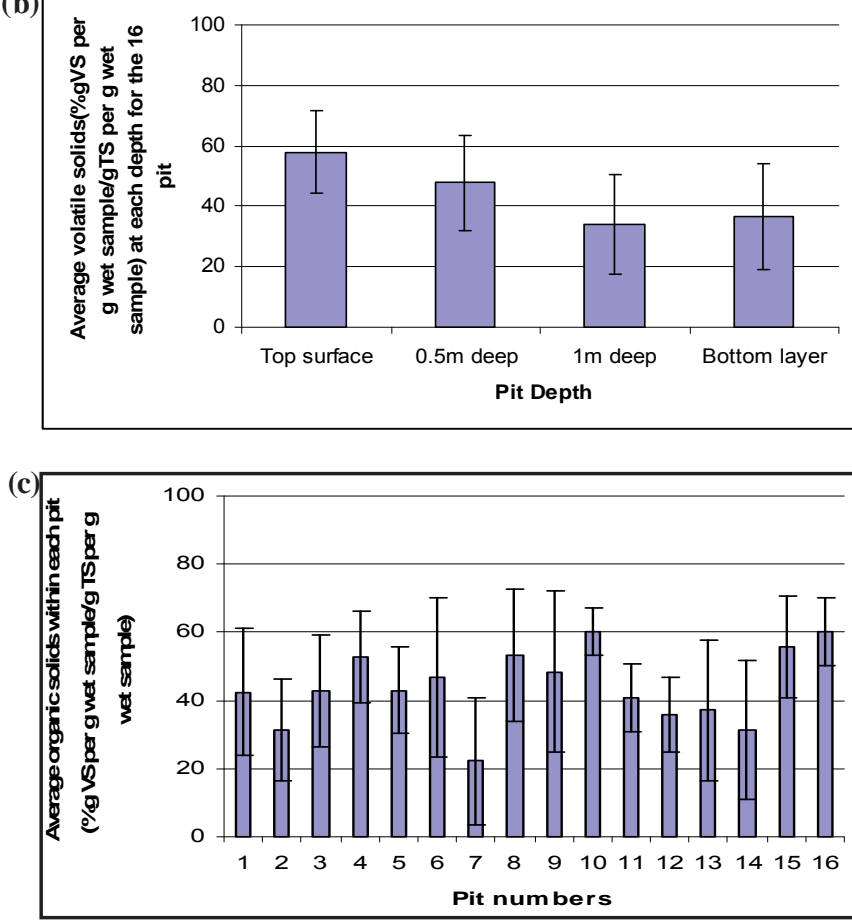

Figure 5

Volatile solid characterisation results (a) for each of the 16 pits from different layers within each pit, (b) average volatile solids at each layer for the 16 pits, (c) average volatile solid within each of the 16 pits. Error bars represent standard deviation.

The most important feature observed from the results, as shown in Fig. 5a, is that for each of the 16 pits investigated the volatile solids as a fraction of the total solids decreases, although not in a regular manner with increasing depth down the pit. This trend is reversed in Pit 16, although this apparent upward trend in volatile solid fraction is not statistically significant. Figure $5 \mathrm{~b}$ shows a decreasing trend in the average volatile solids content as a fraction of total solids for each of the 16 pits, from the top surface to the bottom layer. These suggest that the degree of stabilisation in the pit increases from the top surface to the bottom layer of the pit, leaving only non-volatile (ash-like) components. Figure 5(c) showed that there was a significant variation in the pit-average volatile solids values in all 16 pits analysed.

Regression/correlation analysis undertaken to investigate the relationship between volatile solids as a fraction of total solids and the depth from which samples were collected within the pit using SPSS15 and CurveExpert 1.3. The results showed that there is a significant $(p<0.05)$ linear relationship between volatile solids composition and the different layers from which the samples were collected. Univariate analysis
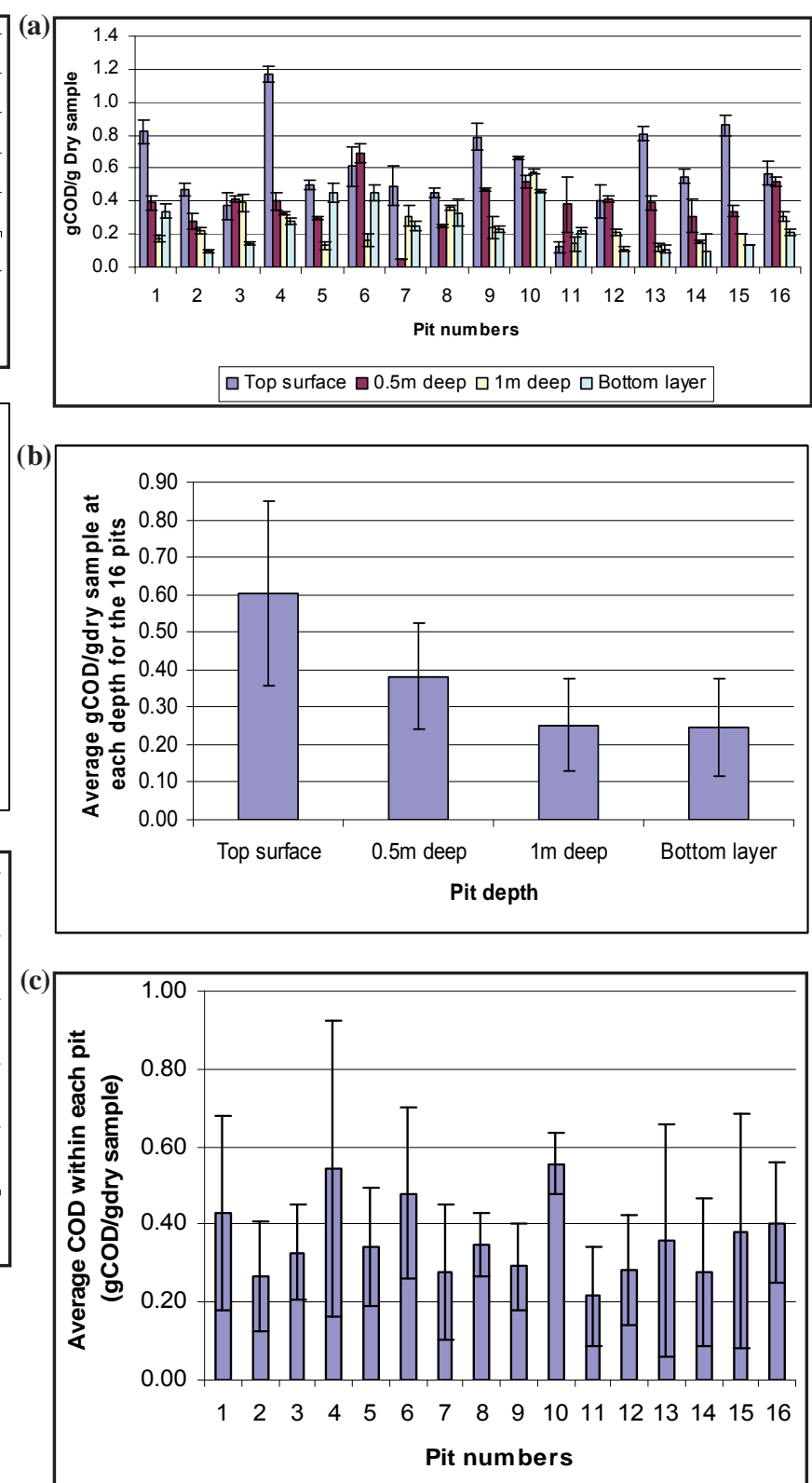

Figure 6

Total COD characterisation results (a) for each of the 16 pits from different layers within each pit (b) average COD at each layer for the 16 pits (c) average COD within each of the 16 pits. Error bars represent standard deviation.

of variance was also performed using SPSS15 with a post-hoc Scheffe test to compare mean values of volatile solids of the different samples collected at different depths. It was found that there was a significant difference between the top layer, $0.5 \mathrm{~m}$ depth and

$1 \mathrm{~m}$ depth in volatile solids, for all samples collected from these depths. There was no significant difference between the values for $1 \mathrm{~m}$ depth and the bottom layer.

Figure 6 presents the COD characterisation results (as g COD/g dried sample).

Chemical oxygen demand (COD) is a measure of the oxidisable organic matter present in samples. It can be used as an indication of the degree of degradation of the pit contents. As shown in Fig. 6a, it is observed that the COD concentration (on a dry basis) at the surface of the pits analysed is 

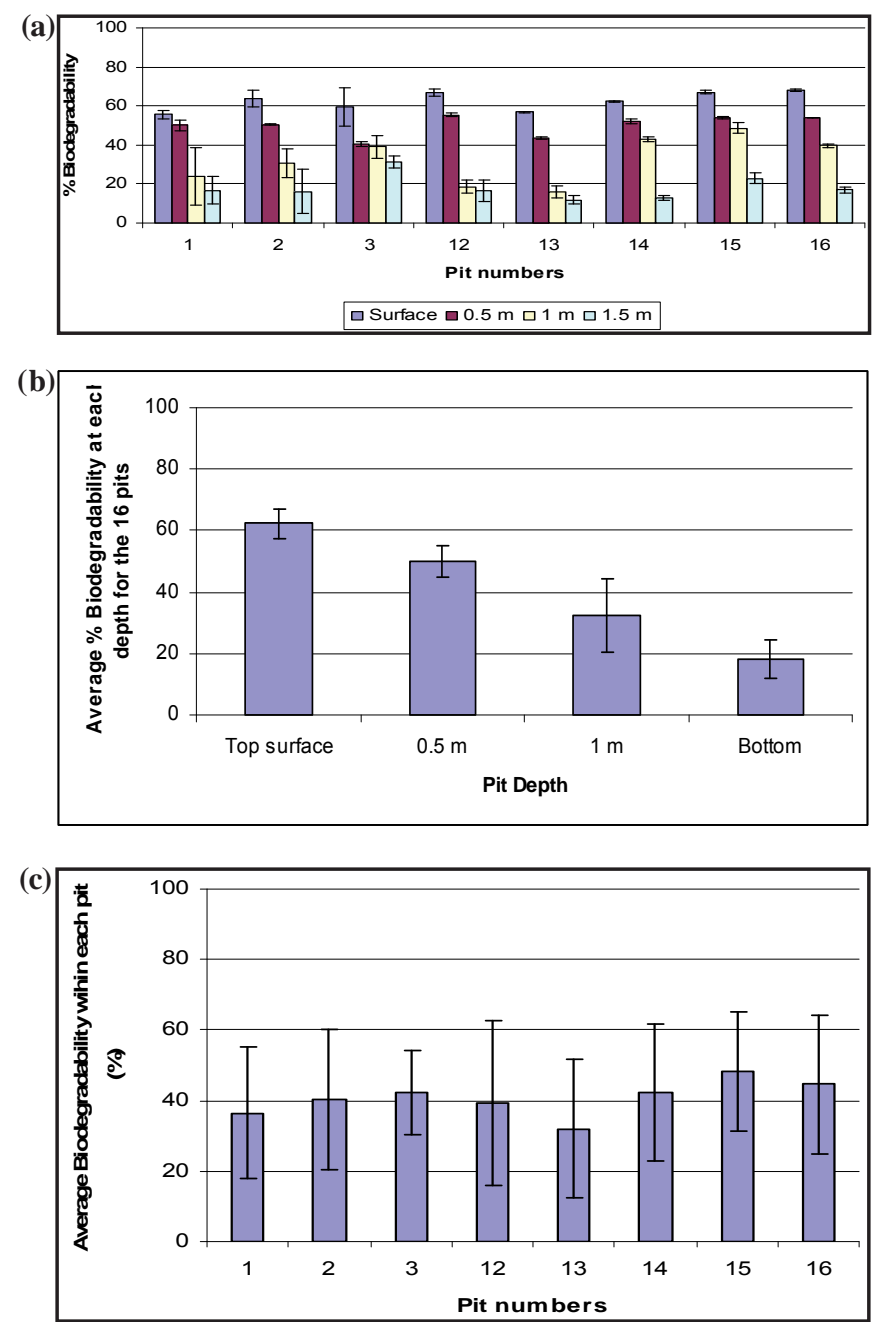

Figure 7

Aerobic biodegradability results (a) for each of the 16 pits from different layers within each pit (b) average biodegradability at each layer for the 16 pits (c) average biodegradability within each of the 16 pits. Error bars represent standard deviation.

significantly higher than that of the bottom layer (except for Pits 5 and 11; Pit 5 has a similar value to the surface and Pit 11 a greater value). Figure $6 \mathrm{~b}$ presents the averages of COD for the 16 pits at different depths. It is observed that the COD in $\mathrm{g} / \mathrm{g}$ dry sample follows a decreasing trend from the surface layer of the pit down to the bottom layer of the pit. This implies that additional degradation/stabilisation occurs down the depth of the pit. It can be seen from Fig. $6 \mathrm{c}$ that the average COD in $\mathrm{g} / \mathrm{g}$ dry sample has a wide variation. Regression/correlation analysis was performed to investigate the relationships between COD concentrations and their depths using SPSS15 and CurveExpert 1.3. The results indicated a linear relationship between COD concentrations and the different layers in which samples were collected. A univariate analysis of variance was also performed using SPSS15 with a post-hoc Scheffe test to compare mean values of COD of the different samples collected at different depth. It was found that there was a significant difference $(p<0.05)$ in COD between all samples collected from different depth except for $1 \mathrm{~m}$ depth and the bottom layer. These results support the Buckley et al. (2008) hypothesis that biological stabilisation is complete after period of time - all older material does not degrade further.
Figure 7 presents the aerobic biodegradability results.

The aerobic biodegradability test gives an estimate of the amount of biodegradable material present in each sample. A low value indicates that the samples contain little biodegradable material and have therefore undergone a significant degree of stabilisation. Due to time and equipment constraints, only half of the total number of samples collected could be analysed, because the delay between sampling and analysis would have been too great for the results to be valid. The biodegradability results for all of the 8 pits analysed followed the same trend. Figure $7 \mathrm{a}$, which presents the biodegradability results at different depths for each of the 8 pits, shows a decreasing trend from the surface layer to the bottom layer of each pit. This suggests that the degree of stabilisation increases from the surface layer to the bottom layer of the pit. The average of the biodegradability of each layer, for the 8 pits analysed (Fig. 7b), showed a decreasing trend from surface layer to bottom layer. This supports the motivating hypothesis that the degree of stabilisation within the pit increases with increasing depth.

Figure $7 \mathrm{c}$ shows that none of the 8 pits had the same degree of stabilisation and the average biodegradability within each of the 8 pits was below 50\%. Regression/correlation analysis showed a linear relationship between biodegradability and the different layers from which samples were collected. A univariate analysis of variance was also performed using SPSS15 with a post-hoc Scheffe test to compare mean values of biodegradability of the different samples collected at different depth. It was found that there was significant difference $(p<0.05)$ in biodegradability between all samples collected from different depth, but for $1 \mathrm{~m}$ depth and the bottom layer $(1.5 \mathrm{~m}$ depth) there was no significant difference.

\section{Discussion}

The study was carried out in eThekwini Municipality where pit conditions are predominantly fairly dry, i.e., there is usually no free liquid on the top surface of the pits. It should be noted that researchers with experience of pit latrines in Asia and other parts of Africa consider those found in eThekwini to be unusually dry. Thus, the degree of stratification in the pit (and therefore limited mixing between layers) may not necessarily be found under different conditions, especially under wet conditions. With that stipulation in mind, it was found that all analytes correlated with biodegradable material, i.e. COD, volatile solids fraction and biodegradable COD decreased significantly between the surface layer sample and the third layer sample, taken from approximately $1 \mathrm{~m}$ below the surface. However, the difference between the $1 \mathrm{~m}$ sample and the bottom sample was not statistically significant. These results support the Buckley et al. (2008) hypothesis that biological stabilisation, otherwise described as the degradation of biodegradable components, occurs in a section of the pit contents that extends from the surface down to a point corresponding with material deposited some years previously, but below this section the material has reached a composition that does not degrade further to any substantial degree with time. This result challenges the common assumption that pit latrines act as storage vessels in which little biodegradation occurs.

From these results, a picture of the life cycle of the pit can be developed: when a pit is first commissioned, or emptied, the material added to the pit is fairly fresh, and to begin with the pit material has undergone little stabilisation. It is all 
similar to Layer (ii) of the Buckley et al. (2008) hypothesis. After a period of time, as material undergoes degradation and gets covered over with fresh material, the bottom layers become anaerobic and partially degraded (Layer (iii) of the Buckley et al. hypothesis) while the new top layer is the Buckley et al. Layer (ii). After a considerable amount of time (years) the bottom layers have undergone degradation to an extent that they cannot degrade further under pit conditions, and may be said to be fully stabilised (Layer (iv)). Once Layer (iv) has established, assuming that the material entering the pit is added at a fairly constant rate and composition, the rate at which the pit latrine contents accumulate is the rate at which Layer (iv) increases since the layers above will move upward in a steady fashion. Thus the rate at which the pit fills is approximately equal to the rate at which material that will ultimately end up as unbiodegradable residue is added to the pit. This is of course a much lower rate than the volume addition rate of fresh pit contents.

The important corollary of this outcome is that the only sustainable way to reduce pit accumulation rate is to reduce the amount of material that will ultimately end up as unbiodegradable residue. Increasing the rate of degradation will only result in the thickness of the combined Buckley et al. (2008) Layers (ii) and (iii) being smaller, which would extend the life of the pit slightly by reducing the average accumulation rate. Alternatively, if it were possible to degrade Layer (iv) contents further than occurs naturally (i.e. changing the yield of non-degradable residue from pit feed material), the amount of material that will ultimately end up as unbiodegradable residue will be a smaller proportion of what is originally added and will have the same net affect. To date, there is no documented method of achieving either of these options.

These results do not indicate at what distance below the surface the interface between the Buckley et al. Layer (iii) and Layer (iv) exists. However if one assumed that the rate of reduction of COD concentration, fraction of volatile solids and biodegradability were constant over the sludge residence time in the pit, a simple linear fit of the data suggests that Layer (iii) extends to approximately $1 \mathrm{~m}$ below the surface of the pit, and that the remainder of the material will not undergo significantly more degradation under the prevailing pit conditions.

\section{Conclusions}

The purpose of this paper was to investigate the variations in the characteristics of sludge content from different ventilated improved pit latrines and the variation in these characteristics at specific depths within each VIP latrine where samples was collected. The measurement did not take into consideration general household waste found in the pit latrines sampled; for practical considerations it only considered the faecal sludge component of the pit. The characterisation results have provided information on the variability of VIP latrine sludge content from one pit to the other and at different layers within a pit. It was found that none of the 16 pits in which samples were collected had the same sludge characteristics despite the fact that all VIPs used in this study were located within similar geological/environmental conditions and that biodegradable material present in faecal sludge found in pit latrines changes with time.

The amount of biodegradable material in terms of COD and organic solid (volatile solid) content decreases down the pits from the surface layer to the bottom, suggesting that changes in sludge content take place with time within a pit. The average COD obtained for faecal material at the surface of the 16 pits investigated was found to be 0.603 gCOD/g dry sample, which is significantly lower than the approximate value of $1.13 \mathrm{gCOD} / \mathrm{g}$ dry sample obtained from the characterisation study of fresh faeces by Nwaneri (2009) and other values reported in the literature, such as that of Almeida (1992) and Lopez (2002). Also, there was a significant difference in the amount of volatile solid $(58 \% \mathrm{gVS} / \mathrm{gTS})$ at the surface of the pit compared to that of faeces $(84 \% \mathrm{gVS} / \mathrm{gTS})$ and the average biodegradability obtained for the surface layer $(52 \%)$ of the pit was found to be significantly lower (80\%) than that of fresh faeces values reported in the literature. This implies that materials present at the surface layer in the pits where samples were collected has undergone a certain degree of stabilisation when compared to the fresh faeces., This also implies that immediately after faeces are deposited in the pit degradation of readily-biodegradable components of the faeces takes place rapidly, if it is assumed that what goes into the pit is adequately represented by the reported values in the literature for the characteristics of fresh faeces. This study has indicated that for relatively dry pit latrines (no free surface of water), physico-chemical analyses of pit latrine contents at different levels in the pit produce profiles for COD concentration, fraction of volatile solids and biodegradable COD that correspond well with the Buckley et al. (2008) hypothesis of processes in pit latrines, and may therefore be regarded as evidence in support of this hypothesis.

The logical consequence of this hypothesis is that the rate at which the pit fills is approximately equal to the rate at which material that will ultimately end up as unbiodegradable residue is added to the pit. This leads to the corollary that the only sustainable way to reduce pit accumulation rate is to reduce the amount of material that will ultimately end up as unbiodegradable residue that is added to the pit, i.e. by eliminating household solid waste from the pit latrine. It may therefore be concluded that considerable variation exists in the organic contents, moisture content and degree of stabilisation of contents from different pits and also that the degree of stabilisation within a pit increases from the surface layer of the pit down through to the bottom layer of the pit.

Finally, it is estimated that the layer of material in the pit that is not fully degraded is approximately $1 \mathrm{~m}$ thick, although this will differ with feed addition rate, pit conditions and pit cross-sectional area.

\section{Acknowledgement}

The research was funded by the Water Research Commission through a project entitled 'Understanding the sludge accumulation in VIPs and other on-site sanitation systems and strategies to manage desludging in the future when pits are full' awarded to Partners in Development (WRC 2011). eThekwini Water and Sanitation Services and Partners in Development are thanked for financial and technical support of this work. Special thanks are offered to Ms C Nwaneri for undertaking part of the laboratory work.

\section{References}

ALMEIDA MC, BUTLER D and FRIEDLER E (1999) At-source domestic wastewater quality. Urban Water 1 49-55. 
APHA (1998) Standard Methods for the Examination of Water and Wastewater (20 ${ }^{\text {th }}$ edn.). American Public Health Association, Washington DC.

BUCKLEY CA, FOXON KM, BROUCKAERT CJ, RODDA N, NWANERI C, BALBONI E, COUDERC A and MAGAGNA D (2008) Scientific Support for the Design and Operation of Ventilated Improved Pit Latrines (VIPs) and the Efficacy of Pit Latrine Additives. WRC Report No. TT 357/08. Water Research Commission, Pretoria.

CHAGGU EJ (2004) Sustainable Environmental Protection Using Modified Pit-Latrines. Ph.D. thesis, Wageningen University, The Netherlands.

DIAMANTOPOULOS A and SCHLEGELMILCH BB (1997) Taking the Fear Out of Data Analysis. The Dryden Press, London.

ENNOS R (2002) Statistical and Data Handling Skills in Biology. Prentice Hall, London, England.

EPA (1995) Decision Maker's Guide to Solid Waste Management, Volume 2. United States Environmental Protection Agency.
URL: www.epa.gov/osw/nonhaz/municipal/dmg2 (Accessed 31 January 2012)

LOPEZ ZAVALA MA, FUNAMIZU N and TAKAKUWA T (2002) Characterization of faeces for describing the aerobic biodegradation of faeces. J. Environ. Syst. Eng. JSCE 720 (VII-25) 99-105.

MARA D (1996) Low-Cost Urban Sanitation. John Wiley \& Sons, Leeds, England.

NWANERI CF (2009) Physico-chemical characteristics and biodegradability of contents of Ventilated Improved Pit latrines in eThekwini Municipality. M.Sc. dissertation, School of Biological and Conservation Science, University of KwaZulu-Natal, South Africa.

PEAVY HS, ROWE DR and TCHOBANOGLOUS G (1985) Environmental Engineering. McGraw-Hill, Singapore.

WRC (WATER RESEARCH COMMISSION) (2011) Knowledge Review 2010/11. Water Research Commission, Pretoria. 
http://dx.doi.org/10.4314/wsa.v38i4.2 Available on website http://www.wrc.org.za

ISSN 0378-4738 (Print) = Water SA Vol. 38 No. 4 July 2012 ISSN 1816-7950 (On-line) = Water SA Vol. 38 No. 4 July 2012 